Article

\title{
The Preparation of Graphene Oxide-Silver Nanocomposites: The Effect of Silver Loads on Gram-Positive and Gram-Negative Antibacterial Activities
}

\author{
Truong Thi Tuong Vi ${ }^{1}$, Selvaraj Rajesh Kumar ${ }^{1}$, Bishakh Rout ${ }^{2}$, Chi-Hsien Liu ${ }^{2}$ (D), \\ Chak-Bor Wong ${ }^{3}$, Chia-Wei Chang ${ }^{3}$, Chien-Hao Chen ${ }^{3}$, Dave W. Chen ${ }^{3, *}$ and \\ Shingjiang Jessie Lue ${ }^{1,4,5, * \text { (iD) }}$ \\ 1 Department of Chemical and Materials Engineering and Green Technology Research Center, \\ Chang Gung University, Taoyuan City 333, Taiwan; truongthituongvi005@gmail.com (T.T.T.V.); \\ rajeshkumarnst@gmail.com (S.R.K.) \\ 2 Department of Biochemical and Biomedical Engineering, Chang Gung University, \\ Taoyuan City 333, Taiwan; bishakh4fun@gmail.com (B.R.); chl@mail.cgu.edu.tw (C.-H.L.) \\ 3 Department of Orthopedic Surgery, Chang Gung Memorial Hospital, Keelung City 204, Taiwan; \\ iborwong@yahoo.com (C.-B.W.); flyinwei@gmail.com (C.-W.C.); chchen1982@gmail.com (C.-H.C.) \\ 4 Department of Safety, Health and Environment Engineering, Ming-Chi University of Technology, \\ New Taipei City 243, Taiwan \\ 5 Department of Radiation Oncology, Chang Gung Memorial Hospital, Taoyuan City 333, Taiwan \\ * Correspondence: mr5181@cgmh.org.tw (D.W.C.); jessie@mail.cgu.edu.tw (S.J.L.); \\ Tel.: +886-2-24313131 (ext. 2613) (D.W.C.); +866-3-2118800 (ext. 5489) (S.J.L.); \\ Fax: +886-2-24332655 (D.W.C.); +886-3-2118700 (S.J.L.)
}

Received: 29 January 2018; Accepted: 9 March 2018; Published: 14 March 2018

\begin{abstract}
In this work, silver nanoparticles (Ag NPs) were decorated on thiol (-SH) grafted graphene oxide (GO) layers to investigate the antibacterial activities in Gram-positive bacteria (Staphylococcus aureus) and Gram-negative bacteria (Pseudomonas aeruginosa). The quasi-spherical, nano-sized Ag NPs were attached to the GO surface layers, as confirmed by using field emission scanning electron microscopy (FESEM) and transmission electron microscopy (TEM), respectively. The average size of GO-Ag nanocomposites was significantly reduced $(327 \mathrm{~nm})$ from those of pristine GO (962 nm) while the average size of loaded Ag NPs was significantly smaller than the Ag NPs without GO. Various concentrations of $\mathrm{AgNO}_{3}$ solutions (0.1, 0.2, and $0.25 \mathrm{M}$ ) were loaded into GO nanosheets and resulted in the Ag contents of 31,43, and 65\%, respectively, with 1-2 nm sizes of Ag $\mathrm{NPs}$ anchored on the GO layers. These GO-Ag samples have negative surface charges but the GO-Ag $0.2 \mathrm{M}$ sample (43\% Ag) demonstrated the highest antibacterial efficiency. At $10 \mathrm{ppm}$ load of GO-Ag suspension, only a GO-Ag $0.2 \mathrm{M}$ sample yielded slight bacterial inhibition (5.79-7.82\%). As the GO-Ag content was doubled to $20 \mathrm{ppm}$, the GO-Ag $0.2 \mathrm{M}$ composite exhibited $\sim 49 \%$ inhibition. When the GO-Ag $0.2 \mathrm{M}$ composite level was raised to $100 \mathrm{ppm}$, almost $100 \%$ inhibition efficiencies were found on both Staphylococcus aureus (S.A.) and Pseudomonas aeruginosa (P.A.), which were significantly higher than using pristine GO (27\% and $33 \%$ for S.A. and P.A.). The combined effect of GO and Ag nanoparticles demonstrate efficient antibacterial activities.
\end{abstract}

Keywords: graphene oxide; silver nanoparticles; thiol groups; antibacterial activity; inhibition efficiencies

\section{Introduction}

In recent years, antibiotic material development has become disputed due to antibiotic resistance. Antibiotic resistance has spread worldwide and threatens our daily life [1]. Even though the exact 
mechanism of the antibacterial function is still being exploited, conventional antibiotics have many defects due to inadequate digestion, urinary limitation, and are rapidly losing effectiveness [2]. Antibiotic resistance has been reported to cause genomic structure mutations resulting in bacteria phenotypes changes to reduce antibiotic efficiency and to develop antibiotic resistance $[3,4]$.

Recently, many researchers found the benefits of graphene oxide (GO) and versatility in drug delivery and biological resources. GO comprises of a typical two-dimensional material made of carbon atoms which are packed densely in a honeycomb crystal lattice [5] and has been used as a promising material for preparing new composites during the past decades [6]. Moreover, it is reported that GO and its composites possess anti-microbial, anti-bacterial, and anti-fungal agents [7,8]. Several studies have shown the effective antibiotics properties using both physical and chemical mechanisms. Zou et al. claimed that the layer structure of GO can wrap the bacteria cell membrane and cause oxidative stress at the basal plane, thus damaging the cellular membrane [9]. When bacteria membranes are exposed to graphite or GO, the oxidation of glutathione, an important cellular antioxidant, occurs [10].

Silver nanoparticles (Ag NPs) are also considered an effective material with antibacterial properties. The bacteria are less prone to develop resistance against Ag NPs than those of conventional antibiotics [11]. Therefore, the combination of Ag NPs and GO is suggested to produce better antibiotic properties than their individual components. The binding between GO and Ag holds good hydrophilicity, high chemical stability, and high oxidization capacity which cause membrane and oxidative stress [12]. The proposed antimicrobial mechanism is that the GO wraps around bacteria while the Ag kills the bacteria with its toxicity [13].

Several previous researchers have synthesized GO nanosheets loaded with Ag NPs using the pulsed [14], microwave [15], and sonication methods [16]. Similar to Ag NPs synthesis, GO-Ag NPs preparation also needs a stabilizer and reducing agents. Previous studies have reported some defects of GO-Ag NPs such as aggregation or the formation of inhomogeneous NPs and the large Ag NPs size. For example, Das et al. prepared the GO-Ag NPs using sodium citrate and sodium borohydride $\left(\mathrm{NaBH}_{4}\right)$ as capping and reducing agents [17]. Haider et al. prepared reduced graphene oxide (rGO) doped with $\mathrm{Ag}$ NPs using a sequence of $\mathrm{AgNO}_{3}$ in aqueous $\mathrm{NaBH}_{4}$ as surfactant [18]. Bao et al. reported GO-Ag NPs composites using $\mathrm{AgNO}_{3}$ as a salt precursor, hydroquinone as the reducing agent, and citrate as the stabilizer [19]. Yet, the size of Ag NPs was still large (ranging from 20 to $80 \mathrm{~nm}$ ) and heterogeneously scattered on the GO layers. Furthermore, the major disadvantage of the previously reported methods gives evidence to the difficulty in controlling the size and distribution, limiting the systematic study on the antibacterial effect [20].

A novel method for GO-Ag NPs synthesis is to use NaSH as an effective cross-linker via GO-SH formation [21]. The benefit of binding thiol groups (-SH) [22] is because it is considered a reactive cross-linker and improves the biological compatibility characteristics of the materials [23]. Moreover, the thiol-functionalized GO could improve the particles' stable suspension in solution to prevent size agglomeration. Besides, GO-SH is an intermediate to bridge the oriented Ag NPs onto the GO's functional groups, enabling precise particle size control. In this study, our aims are to produce a few nanometer-sized Ag NPs on GO without using extra reducing agents and stabilizers and also to investigate the optimal Ag NPs and GO ratio for high antibacterial activity.

In this study, we fabricated the thiol grafted GO-Ag nanocomposites to investigate their antibacterial activities on Staphylococcus aureus (S.A., Gram-positive) and Pseudomonas aeruginosa (P.A., Gram-negative) bacteria. Different loads of a few nanometer-sized Ag nanoparticles $(<5 \mathrm{~nm})$ on GO were prepared using various concentrations of a silver precursor $\left(\mathrm{AgNO}_{3}\right)$ solution to optimize the Ag:GO ratio. Solutions containing 10-100 ppm of GO-Ag nanomaterial were compared for antibacterial efficiency. Our study offers an in-depth understanding of the role of smaller sized Ag loadings in the nanocomposite, further emphasizing its promising potential for higher antibacterial agents and possible biomedical applications. 


\section{Results and Discussion}

\subsection{Structural and Morphological Properties of Graphene Oxide (GO) Nanosheets}

The pristine GO was observed as wrinkled and wavy when dried in a vacuum oven as shown in Figure 1a. The corresponding transmission electron microscope image indicates that the GO had a flaky, smooth, and paper-like structure (Figure 2c). The GO average size was measured using the dynamic light scattering (DLS, Zetasizer, 2000 HAS, Malvern, Worcestershire, UK) technique. The average hydrodynamic diameter (AHD) of GO was recorded at $962.83 \pm 141 \mathrm{~nm}(n=3)$. The typical sharp X-ray diffraction peak (001) at $2 \theta$ of $11.7^{\circ}$ confirms the formation of GO (Figure 3a) [8,24]. The calculated $\mathrm{d}$-spacing of the GO is $0.76 \mathrm{~nm}$.
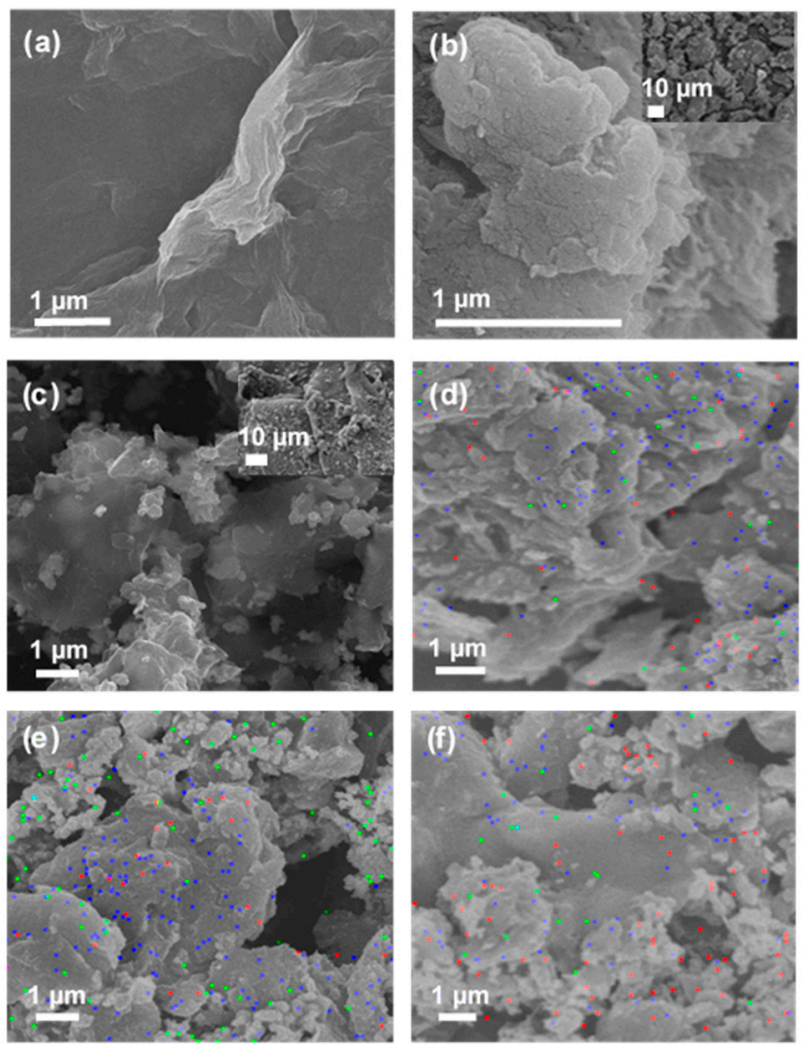

Figure 1. The field emission scanning electron microscope (FESEM) images of (a) pristine graphene oxide (GO); (b) thiol grafted graphene oxide (GO-SH); and (c) GO-Ag 0.2 M composites; FESEM mapping of (d) GO-Ag 0.1 M; (e) GO-Ag 0.2 M; and (f) GO-Ag 0.25 M composites. The red, blue, and green colors represent the elemental distributions of $\mathrm{Ag}, \mathrm{C}$, and $\mathrm{O}$.

To analyze the carbon bond structure, Raman spectroscopy (Labram Hr800, Horiba, Ltd., Kyoto, Japan) was employed to examine the differences between the commercial graphite and synthesized GO samples. As shown in Figure $3 b$ for the GO sample, the $G$ band $\left(1348 \mathrm{~cm}^{-1}\right)$ is significantly higher than the D band $\left(1583 \mathrm{~cm}^{-1}\right)$ compared to graphite. When GO was oxidized from graphite, the $I_{\mathrm{D}} / I_{\mathrm{G}}$ ratio greatly increase from 0.28 to 0.86 . The $\mathrm{sp}^{2}$ carbon bonding was broken by the oxidation process and transformed into $\mathrm{sp}^{3}$ bonding. Moreover, a Fourier-transform infrared spectroscopy (FTIR) analysis of the GO spectra (Figure 4a) indicated peaks at 3404, 1718, 1625, and $1055 \mathrm{~cm}^{-1}$ corresponding to the $\mathrm{C}-\mathrm{OH}$ (hydroxyl), $\mathrm{C}=\mathrm{O}, \mathrm{C}=\mathrm{C}$ (possibly due to the skeletal vibration of oxidized graphite domains), and the $\mathrm{C}-\mathrm{O}$ stretching vibrations, respectively. The presence of those oxygen-containing groups (carboxyl, hydroxyl, and epoxy groups) confirmed the successful synthesis of the GO [24]. To further investigate the chemical structure, X-ray photoelectron spectroscopy (XPS) was utilized to study the bonding groups. Figure $4 b, c$ revealed 
the overall and the $C 1$ s deconvolution XPS spectra of the main GO's bonding groups. The unique peaks attributed at 284.4, 285.8, 287, and $288.5 \mathrm{eV}$ correspond to $\mathrm{C}-\mathrm{C}, \mathrm{C}-\mathrm{O}, \mathrm{C}=\mathrm{O}$, and $\mathrm{O}-\mathrm{C}=\mathrm{O}$ groups, respectively [25]. A full scan spectra of GO showed the C/O ratio around 3:1.
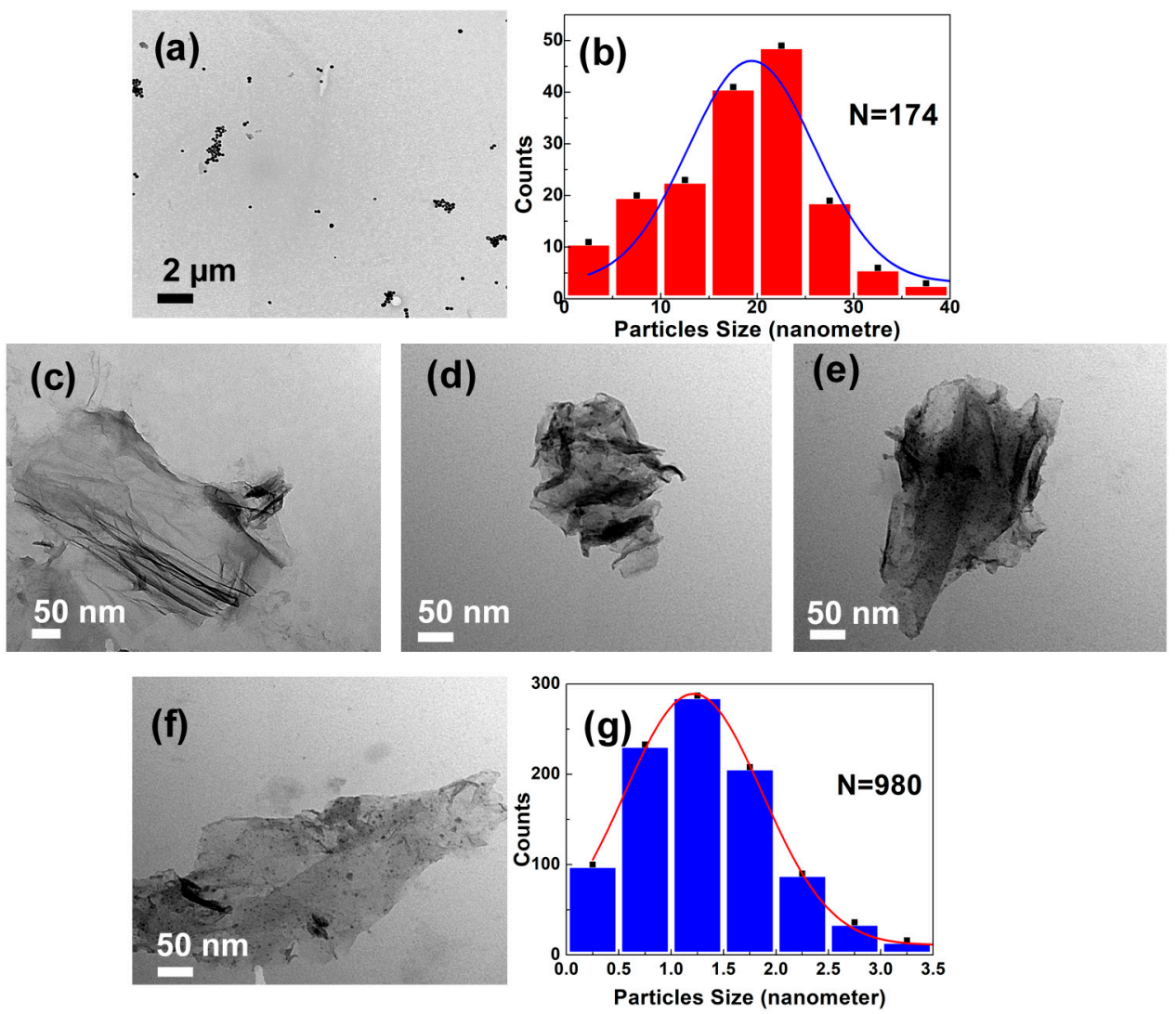

Figure 2. (a) Transmission electron microscope (TEM) images of pristine silver nanoparticles (Ag NPs) and their (b) particle size distributions without being grafted on GO; (c) pristine GO; (d) GO-Ag $0.1 \mathrm{M}$; (e) GO-Ag 0.25 M; (f) GO-Ag 0.2 M composites; and (g) the Ag particle size distributions of GO-Ag $0.2 \mathrm{M}$ composites.

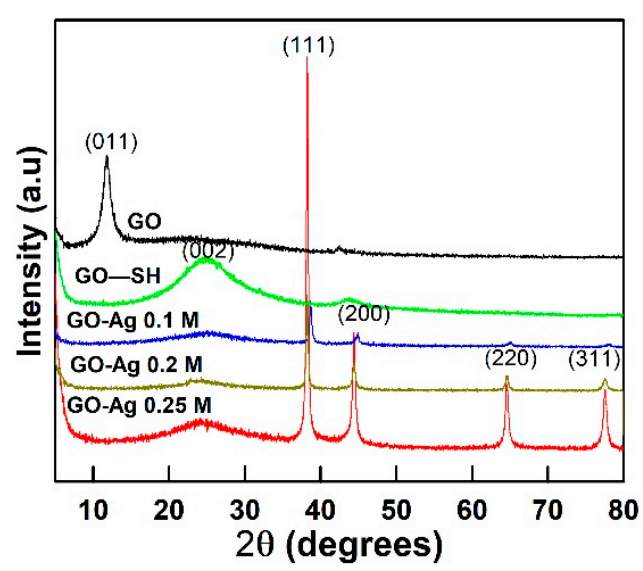

(a)

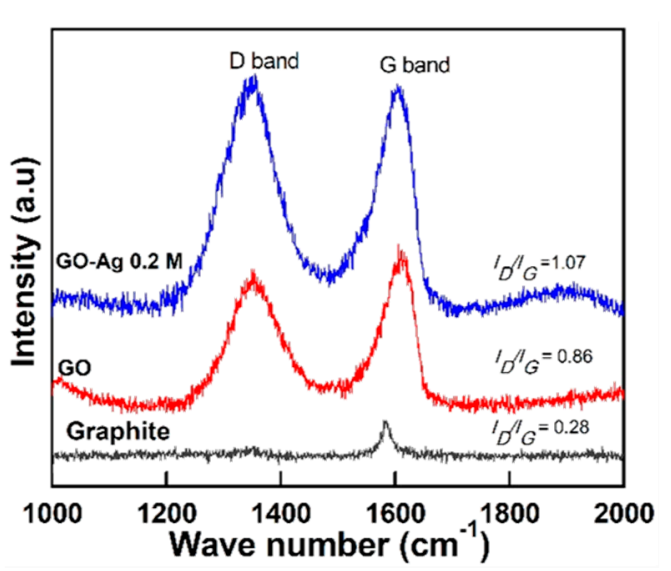

(b)

Figure 3. (a) The XRD graph of GO, GO-SH, GO-Ag 0.1 M, GO-Ag 0.2 M; and GO-Ag 0.25 M composites and (b) Raman analysis of graphite, GO, and GO-Ag 0.2 M composites. 


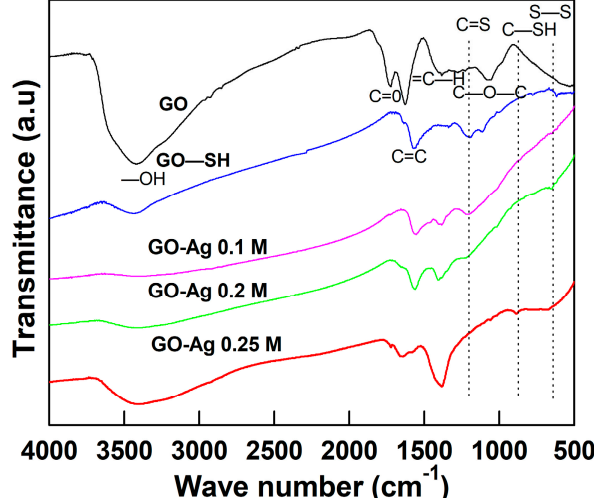

(a)

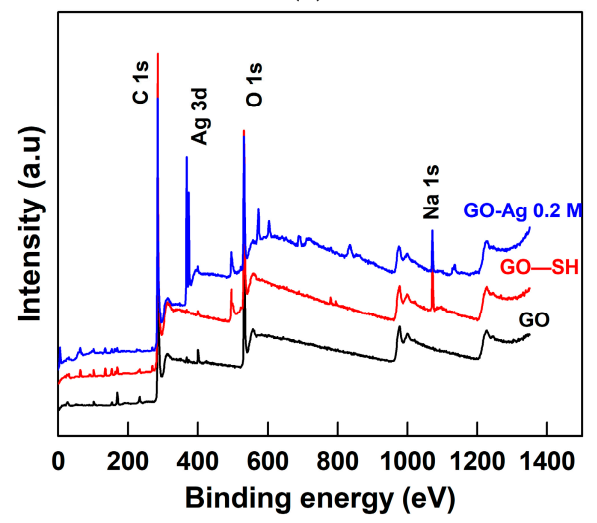

(b)

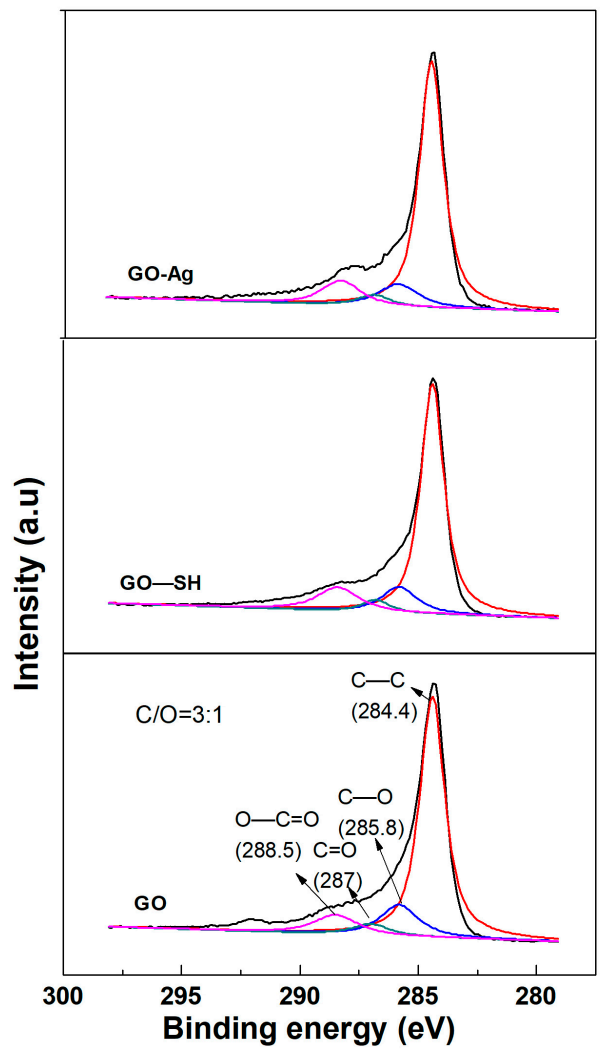

(c)

Figure 4. FTIR analysis of (a) GO, GO-SH, GO-Ag 0.1 M, GO-Ag 0.2 M, and GO-Ag 0.25 M composites; (b) XPS full scans of GO, GO-SH, and GO-Ag 0.2 M composites; and (c) C 1s deconvolution spectra of GO, GO-SH, and GO-Ag $0.2 \mathrm{M}$ composites.

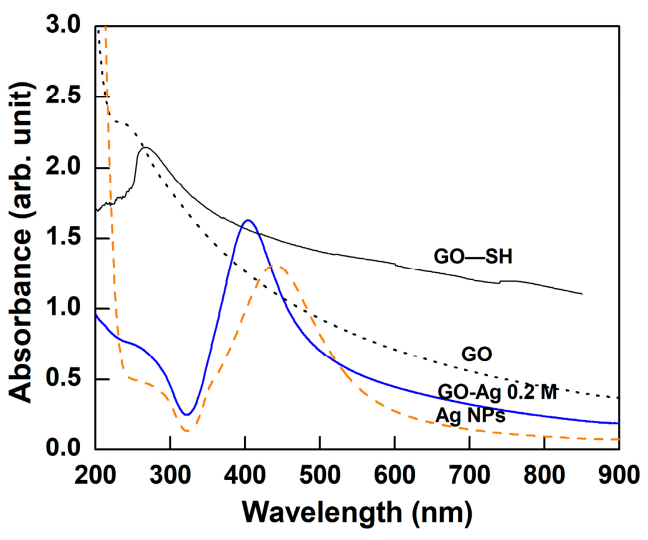

(a)

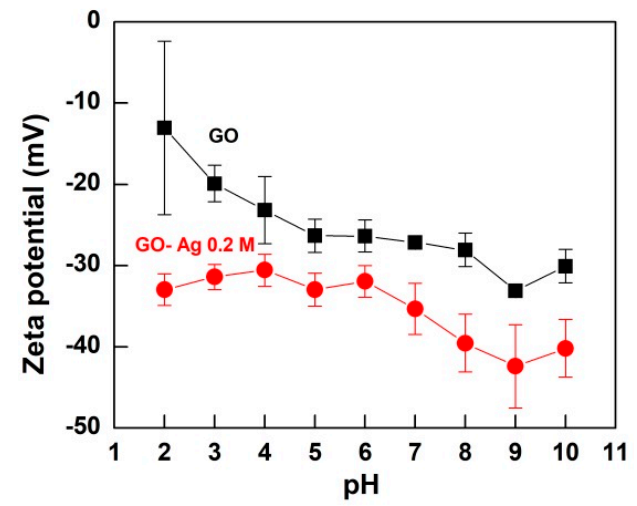

(b)

Figure 5. (a) UV-visible spectra of pristine GO, pristine Ag nanoparticles, GO-SH, and GO-Ag 0.2 M composite; (b) zeta potential profiles of pristine GO and GO-Ag $0.2 \mathrm{M}$ composite.

UV-visible analysis of pristine GO was shown in Figure 5a. Typical peaks at around 230 and $310 \mathrm{~nm}$ correspond to the $\pi-\pi^{*}$ electronic transition of the $\mathrm{C}=\mathrm{C}$ aromatic bonds and $n-\pi^{*}$ electronic transition of the $\mathrm{C}=\mathrm{O}$ bonds [26]. The surface charge of $\mathrm{GO}$ ranged from 28.2 to $30.3 \mathrm{mV}$, indicating the moderate stability of the GO nanosheets as shown in Figure 5b [27]. In addition, there was a relative linear negative response of zeta potential of the GO as the $\mathrm{pH}$ value increasing from 2 to 10 . 
This phenomenon is reasonable due to the effect of the carboxylic and hydroxyl groups ionizing causing an increase in the $\mathrm{pH}$ value.

The pristine GO nanosheets were degraded in the air's atmosphere as indicated in the thermal gravimetric analysis (TGA) as shown in Figure 6. The GO exhibited three stages of weight loss. The first peak dropped from 25 to $100{ }^{\circ} \mathrm{C}$ due to the removal of water from the remaining moisture. Other noticeable region weight losses were from 150 to $250{ }^{\circ} \mathrm{C}$ and from 400 to $500{ }^{\circ} \mathrm{C}$. The former peak around $180^{\circ} \mathrm{C}$ is ascribed to the removal of the oxygen functional groups from the GO's surface while the other sharp peak around $450{ }^{\circ} \mathrm{C}$ is related to the burning of the carbon constituting graphene sheets [28]. The GO was completely degraded in the air flow at a temperature of $490{ }^{\circ} \mathrm{C}$.

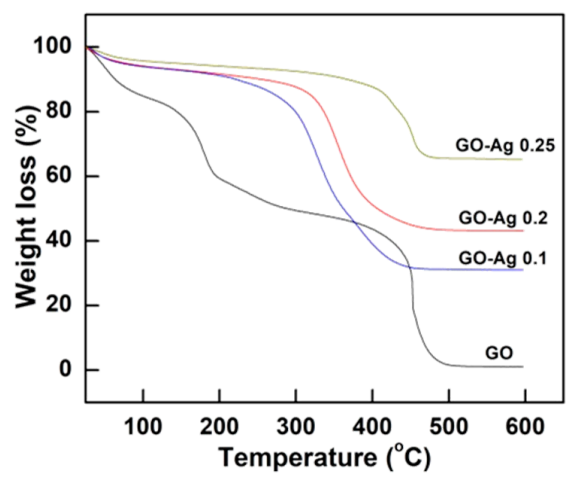

Figure 6. TGA weight loss of GO, GO-Ag 0.1 M, GO-Ag 0.2 M, and GO-Ag 0.25 M composites.

\subsection{Structural and Morphological Properties of GO-SH Particles}

When $\mathrm{NaSH}$ reacted with $\mathrm{GO}$, the nanosheets tended to be broken into many disoriented fragments during sonication and the stirring process. The GO-SH sample also has a sheet-like structure with agglomerations as shown in the field emission scanning electron microscope (FESEM) images (Figure 1b). The X-ray diffraction (XRD) spectrum of GO-SH sample shows the broadened peak at $2 \theta=25^{\circ}$ in Figure 3a which indicates the contribution of $-\mathrm{SH}$ group [29]. This was clearly confirmed by FTIR characteristic peaks at 1200,620 , and $838 \mathrm{~cm}^{-1}$ corresponding to the $\mathrm{C}=\mathrm{S}$ stretch, S-S weak peak, and the secondary bond of thiol group C-SH bending, respectively (Figure 4a) [30]. The UV-visible spectra showed the obvious peak of absorbance in the GO-SH samples at $267 \mathrm{~nm}$, which indicated the excited transition by capped-thiol groups at the terminated aromatic graphene oxide [31] (Figure 5a). Besides this, the XPS peak at $1071 \mathrm{eV}$ confirms the appearance of sodium ions during the thiolation process (Figure $4 \mathrm{~b}$ ) [32]. The XPS analysis revealed that more $\mathrm{O}-\mathrm{C}=\mathrm{O}$ groups were formed in the GO-SH sample than the GO (13.2\% versus $10.1 \%$, Table 1$)$. It was reported that the $\mathrm{C} 1 \mathrm{~s}$ carbonate component $(\mathrm{O}-\mathrm{C}=\mathrm{O})$ overlaps with adventitious carbon, increasing the ionization potential while having strong vibrations [33].

Table 1. Bonding composition percentage of X-ray photoelectron spectroscopy (XPS) survey.

\begin{tabular}{ccccc}
\hline \multirow{2}{*}{ Samples } & \multicolumn{4}{c}{ Carbon Bonding } \\
\cline { 2 - 5 } & C-C & C-O/C-S & C=O & O=C-O \\
\hline GO & 70.7 & 14.1 & 5.1 & 10.1 \\
GO-SH & 70.1 & 12.2 & 4.6 & 13.2 \\
GO-Ag 0.2 M & 72.5 & 11.2 & 4.6 & 11.7 \\
\hline
\end{tabular}

\subsection{Structural and Morphological Properties of GO-Ag Composites}

FESEM images and elemental mappings of GO-Ag samples with different $\mathrm{AgNO}_{3}$ concentrations are shown in Figure 1c-f. The Ag NPs were distributed on the GO nanosheets as primary nanoparticles. 
Moreover, the fine Ag NPs were attached on the GO sheets, indicating that there was strong bonding between GO-SH and the Ag NPs. The TEM images in Figure 2d-f indicated that the Ag NPs appeared as small dots on the GO nanosheets. The size distribution histogram of Ag NPs anchored on GO sheets was fitted with Gaussian curves to obtain the particle-size distribution $(1.24 \mathrm{~nm})$, as presented in Figure $2 \mathrm{~g}$. The narrow and uniform Ag NPs size on GO sheets is relatively consistent with the previous study with average size Ag NPs on GO sheets of approximately $2 \mathrm{~nm}$ [34]. The GO-Ag NPs showed a sharper UV-visible peak at $401 \mathrm{~nm}$ than pure Ag NPs at $443 \mathrm{~nm}$ (Figure 5a), indicating the successful Ag NP formation on the GO sample. This is in agreement with Lukman et al. [35] who reported 390-470 nm for Ag NPs, depending on the particle shape and size. The broad peak of $267 \mathrm{~nm}$ present in the GO-SH sample diminished in the GO-Ag nanocomposite, indicating that this thiol group was consumed during the Ag NPs formation. Without using NaSH and GO nanosheets, the synthesized particle size of the Ag NPs was much larger (19 nm) (Figure 2a,b). This confirms that the NaSH was efficient to reduce the Ag particle size. After attachment with Ag NPs, however, the mean size for the GO sheets dramatically reduced to $324 \pm 20 \mathrm{~nm}(n=3)$, which was significantly smaller than pristine $G O(962 \pm 141 \mathrm{~nm})$. This may be due to breaking of the GO sheets into fragments via sonication, thus reducing the size [36].

The energy-dispersive X-ray (EDX) with FESEM mapping indicated that the Ag weight percentage increased for GO-Ag from 0.1 to $0.25 \mathrm{M}$. The Ag weight percent loaded on the GO sheets (as shown in Table 2) was 32.4, 44.3, and $62 \%$ using $0.1,0.2$, and $0.25 \mathrm{M}$ of $\mathrm{AgNO}_{3}$, respectively. The GO-Ag composite shifted the main XRD peaks to $38.1^{\circ}, 44.3^{\circ}, 64.5^{\circ}$, and $77.5^{\circ}$ in Figure $3 \mathrm{a}$, which are assigned to the (111), (200), (220), and (311) crystal lattice planes of face-centered cubic Ag NPs, respectively. However, the typical GO peak at $11.7^{\circ}$ disappeared in the GO-Ag samples due to the Ag NPs attached to the interlayers and covering the signals of GO peaks [37]. Prominently, the sharp peak at $38.1^{\circ}$ confirmed the pure crystalline Ag NPs [38]. The Ag peak intensity increased steadily for GO-Ag from 0.1 to $0.25 \mathrm{M}$, reflecting different Ag contents in each sample. Besides this, Figure $3 \mathrm{~b}$ shows the Raman spectra absorbance. After bonding with Ag NPs, the peak intensities increased with the G and D band at 1604 and $1354 \mathrm{~cm}^{-1}$, respectively. The ratio intensity of $I_{\mathrm{D}} / I_{\mathrm{G}}$ increased for GO from 0.86 to 1.07 , indicating that a new defect was created during the Ag NPs formation process. In the GO-Ag FTIR analysis indicated in Figure 4a, the -OH groups become broadened while the intensity related to the bonding slightly decreased due to the interactions between $\mathrm{Ag}^{+}$ions and the oxygen-containing groups on the GO sheets [39]. Remarkably, the peak of the $\mathrm{C}=\mathrm{C}$ of sp ${ }^{3}$ clearly appeared in the GO-Ag samples at $1564 \mathrm{~cm}^{-1}$ during the Ag NPs formation attachment to GO sheets. The FTIR results confirm that the GO-Ag NPs, via grafting with the -SH group, were successfully synthesized.

Table 2. The energy dispersive X-ray spectroscopy (EDX) elemental composition (at \%) for Ag NPs attached on the GO sheet layers.

\begin{tabular}{cccc}
\hline Samples & C & O & Ag \\
\hline GO-Ag 0.1 M & 49.2 & 18.3 & 32.4 \\
GO-Ag 0.2 M & 38.5 & 17.1 & 44.3 \\
GO-Ag 0.25 M & 21.5 & 16.5 & 62.0 \\
\hline
\end{tabular}

The XPS full scan analysis (Figure 4b) exhibited that the sharp peak at $368 \mathrm{eV}$ confirmed that the Ag element was attributed to the GO-Ag sample. The $\mathrm{C}-\mathrm{C}$ curve relatively increased while the $\mathrm{O}-\mathrm{C}=\mathrm{O}$ bonding was also partially reduced (from $13.2 \%$ in GO-SH to $11.7 \%$, Figure $4 \mathrm{c}$ and Table 1 ) during the silver attachment process [40]. However, the content of carboxyl functional groups was higher in the GO-Ag composite than in the GO sample.

The increased carboxyl acid groups in the GO-Ag are attributed to the lower zeta potential values than the GO sample (Figure 5b). GO-Ag exhibits a higher negative charge due to the ionization of the multiple surface functional groups $(-\mathrm{SH})$, and the products were dipped in alkaline solution during the synthesis process. This result also indicates that the chemical bonding with the thiol group modified the inherent surface zeta potential of the GO nanosheets, implying higher dispersion and stability in 
GO-Ag. Moreover, the zeta potential value of GO-Ag has less variation and more negative charge than the GO sample. This result indicated that GO-Ag is more stable than GO.

TGA (Figure 6) was applied to analyze the weight loss at room temperature up to $600{ }^{\circ} \mathrm{C}$ in order to estimate the leftover Ag amount on the GO sheets [41]. The Ag content was 31\% in GO-Ag $0.1 \mathrm{M}$ while the percentages were $43 \%$ and $65 \%$ which correspond to the samples of GO-Ag $0.2 \mathrm{M}$ and GO-Ag $0.25 \mathrm{M}$ composites, respectively (Figure 6).

Based on the above results, a mechanism was proposed to illustrate the chemical reaction process. Graphene oxide composed with the basal planes and the edges containing oxygen groups including epoxy, hydroxyl, and carboxyl groups [42]. Therefore, it is easy to disperse in water due to its high hydrophilicity, leading to its break-up into the fragments when it was sonicated for a long time. When NaSH was added, the site of -SH was anchored to the basal of the epoxy group due to orthogonal reactions of the $-\mathrm{SH}$ groups to selectively functionalize one site over another to form $\mathrm{GO}-\mathrm{SH}$. Thiolate GO may exhibit an in-specific binding capability towards the nanocrystal structure due to a high affinity towards Ag NPs [43]. On the other hand, the GO-SH mixture and an aqueous $\mathrm{AgNO}_{3}$ is embedded in a $\mathrm{NaOH}$ solution without any conventional reducing agents. The - $\mathrm{SH}$ groups acts as a binder and binds the Ag NPs to the GO through the phenolate anions of GO that are transformed into semiquinones [44]. With the presence of $\mathrm{NaOH}$ and the cross-linker GO-SH, the reduction reaction of $\mathrm{Ag}^{+}$to form the Ag NPs was accelerated and oriented at the basal plane of the GO structure. Since we have fabricated a series of GO-Ag samples with various GO/Ag ratios, we will examine their antibacterial efficiency and search for the optimal GO/Ag ratio.

\subsection{Antibacterial Results}

\subsubsection{Antibacterial Activity at a Low Concentration of $10 \mathrm{ppm}$}

Staphylococcus aureus (S.A.) and Pseudomonas aeruginosa (P.A.) represent the positive and negative Gram bacteria used to measure the optical density (OD) with the $600 \mathrm{~nm}$ wavelength. At a low concentration of $10 \mathrm{ppm}$, Figure 7 showed that the number of bacteria was slightly increased proportionally to the $\mathrm{AgNO}_{3}$ concentration whereas almost no inhibition was observed in the GO sample. The inhibition of GO-Ag $0.1 \mathrm{M}$ was $0.82 \%$ and $1.69 \%$ for S.A. and P.A., respectively. The GO-Ag $0.2 \mathrm{M}$ had an inhibition efficiency of $5.79 \%$ and $7.82 \%$ for S.A. and P.A., respectively. Thus, the higher antibacterial activity of GO-Ag on P.A. rather than of S.A. may be due to the membrane structure difference. The gram-positive bacteria have a thick multilayered peptidoglycan of 20-30 nm while the Gram-negative one has a thinner membrane $(8-12 \mathrm{~nm})$ and is more vulnerable to antibiotics. This is the reason why S.A. is more resistant than P.A. [45].

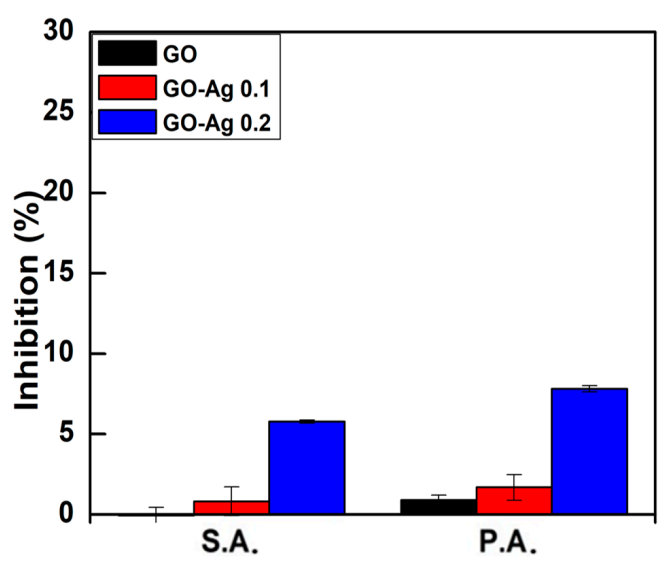

Figure 7. The inhibition percentages of the P.A. and S.A. bacteria treated with pristine GO, GO-Ag $0.1 \mathrm{M}$, and GO-Ag $0.2 \mathrm{M}$ composites at a concentration of $10 \mathrm{ppm}$. 


\subsubsection{Antibacterial Activity at a Concentration of $20 \mathrm{ppm}$}

To investigate the contribution of the thiol (-SH) group to the GO-Ag composite formulation and the effect of Ag contents in GO-Ag NPs, a series of 20 ppm solutions were prepared for this test with S.A. bacteria. Figure 8 indicated that the GO had no inhibition (almost $0 \%$ ) while GO-SH exhibited little antibacterial activity (10.8\%), which was lower than the $0.1 \mathrm{M} \mathrm{GO}-\mathrm{Ag}(16.7 \%)$ and $0.2 \mathrm{M} \mathrm{GO}-\mathrm{Ag}$ $(48.77 \%)$, respectively. Interestingly, we found that the inhibition of $0.25 \mathrm{M}$ GO-Ag was reduced to $19.21 \%$. Pure Ag NPs has an inhibition rating of 28.7\%. This result showed that the Ag NPs may be the main factor which contributes to the antibacterial efficiency.

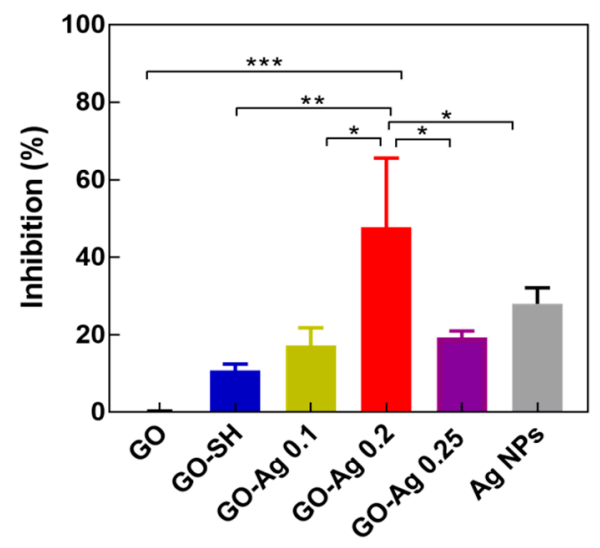

Figure 8. The inhibition percentage of S.A. bacteria treated with pristine GO and GO-Ag composite samples at a concentration of $20 \mathrm{ppm}\left({ }^{*}, * *\right.$ and ${ }^{* * *}$ were represented for $p<0.05, p<0.01, p<0.001$, respectively).

The higher Ag load in the $0.25 \mathrm{M}$ sample did not benefit the antibacterial effect. The TEM images of Ag NPs in GO-Ag 0.25 M (Figure 2e) shows some Ag agglomerates, which may reduce the contact surface area of Ag NPs with bacteria. The GO-SH's antibacterial function may be associated with the fact that the thiol group (-SH) reacted with GO to form a disulfide bond (S-S) which converts G-SH to glutathinone sulfide (G-S), causing oxidative stress to the cell [12,46]; especially when thiol was bonded with Ag NPs [47]. GO-Ag 0.2 M had the highest antibacterial capacity. The optimal Ag content was found to be approximately 42\%, lower than the finding of Tang et al. (50\% with $50 \mathrm{~nm} \mathrm{Ag}$ NPs [48]). Since it has been reported that GO is the substrate that helps the mechanical immobilization meanwhile Ag NPs on the GO sheets will kill bacteria [48,49]. The relative amount between GO and Ag NPs needs to be balanced. The smaller sized Ag NPs in this work can reduce the effect of the Ag load for antibacterial treatment.

\subsubsection{Antibacterial Activity at a Concentration of $100 \mathrm{ppm}$}

A high 100 ppm concentration of GO and GO-Ag 0.2 M composite was selected in further tests to compare their efficiency. The inhibition of S.A. (27.24\%) was significantly lower than P.A. (32.86\%) when using the GO sample. The GO-Ag resulted in an almost 100\% inhibition (Figure 9a). It was reported that the GO performed the antibacterial effect at concentrations in the range of 10-500 ppm, depending on the oxidation level of the GO [8,12,24]. With the Ag NP modified GO, the inhibition concentration of the composites would be reduced. Moreover, Figure $9 \mathrm{~b}$ shows that the bacterial inhibition level had a positive trend with the GO-Ag concentration of 10-100 ppm. This study demonstrates a promising effect for the antibacterial activity using appropriately designed GO nanocomposites at suitable concentrations. Further study is underway to determine the bacteria resistance and the associated gene expression of the bacteria in response to long-term exposure to the GO-Ag samples. 


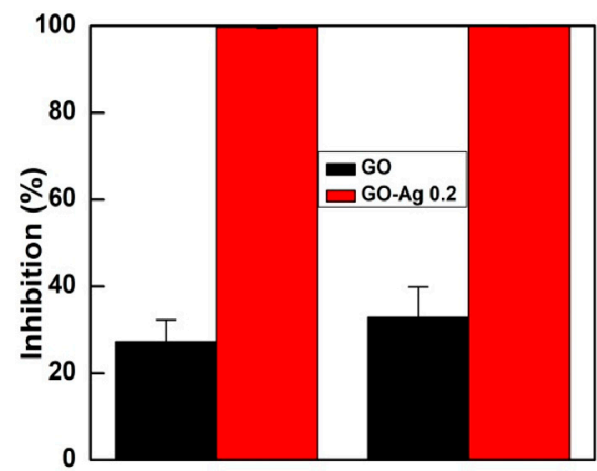

S.A.
P.A.

(a)

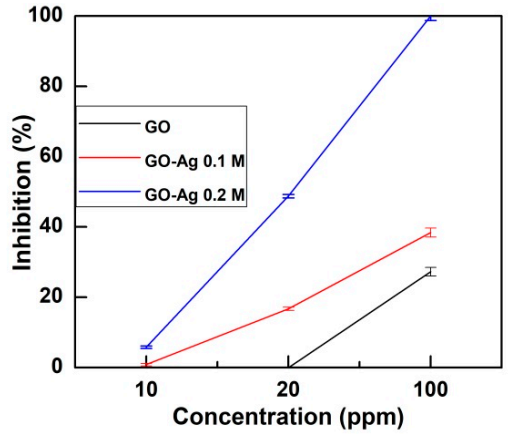

(b)

Figure 9. (a) The inhibition percentage of P.A. and S.A. bacteria treated with GO and GO-Ag $0.2 \mathrm{M}$ samples at a concentration of $100 \mathrm{ppm}$; and (b) the antibacterial inhibition percentage of GO, GO-Ag 0.1, and GO-Ag 0.2 composites as a function of the load concentration against S.A. bacteria.

\section{Materials and Methods}

\subsection{Materials}

Graphite powder, sodium hydrosulfide $(\mathrm{NaSH})$, and an ammonium hydroxide solution $\left(\mathrm{NH}_{3}\right.$, $25 \%)$ were purchased from Sigma-Aldrich, St. Louis, MO, USA. Potassium permanganate $\left(\mathrm{KMnO}_{4}\right)$ and trisodium citrate $\left(\mathrm{Na}_{3} \mathrm{C}_{6} \mathrm{H}_{5} \mathrm{O}_{7}\right)$ were purchased from Nihon Shiyaku Industries Ltd., Osaka, Japan. The sulfuric acid $\left(\mathrm{H}_{2} \mathrm{SO}_{4}\right)(95-98 \%)$ solution was purchased from Scharlab S.L., Barcelona, Spain. The silver nitrate $\left(\mathrm{AgNO}_{3}\right)$ was purchased from Mallinckrodt Baker Inc., Paris, France and the hydrochloric acid ( $\mathrm{HCl})$ was purchased from Showa chemical co., Ltd., Honshu, Japan.

\subsection{Bacterial Strains}

S.A. (ATCC 25178) and P.A. (BCRC 12154) were obtained from the Bioresource Collection and Research Center in Hsinchu, Taiwan. The Difco ${ }^{\mathrm{TM}}$ Nutrient broth and phosphate-buffered saline (PBS) were purchased from Sigma-Aldrich, St. Louis, MO, USA.

\subsection{Synthesis of GO}

The GO was synthesized via a modified Hummer's method [50] using graphite, $\mathrm{H}_{2} \mathrm{SO}_{4}$, and $\mathrm{KMnO}_{4}$ as the oxidizing agents. Around $2.4 \mathrm{~g}$ of graphite powder was dissolved in the $300 \mathrm{~mL} \mathrm{H}_{2} \mathrm{SO}_{4}$ solution and stirred for $10 \mathrm{~min}$. Subsequently, an amount of $2.4 \mathrm{~g} \mathrm{KMnO}_{4}$ was added. Additional amounts of $\mathrm{KMnO}_{4}$ were added when the green color of $\mathrm{MnO}^{3-}$ diminished. A total of 5 equivalent weights of $\mathrm{KMnO}_{4}$ were sequentially added. After the $\mathrm{MnO}^{3-}$ was completely oxidized, $400 \mathrm{~g}$ of ice was added to the solution while keep in the ice bath to reduce the increasing temperature reaction. The solution was kept in the bath for a few days until the separation of the precipitation was clearly observed. The upper solution was removed, while the remaining precipitate was washed with deionized (DI) water in centrifugation (Hitachi, Tokyo, Japan) until the pH became neutral. The gel-like products were then dried at $60^{\circ} \mathrm{C}$ in vacuum conditions overnight.

\subsection{Synthesis of Ag NPS}

The Ag NPs were synthesized using trisodium citrate as a reducing agent by a modified Turkevich method [51]. In brief, $1 \mathrm{mM} \mathrm{AgNO} 3$ was dissolved in $60 \mathrm{~mL}$ DI water and continuously stirred at $200 \mathrm{rpm}$. Afterwards, the solution was vigorously boiling at $90^{\circ} \mathrm{C}$. Then, $6 \mathrm{~mL}$ of $10 \mathrm{mM}$ trisodium citrate was added dropwise until the color of the solution turned into a bright yellow color. The final solution was allowed to cool at room temperature and then stored in a dark place for further usage. 


\subsection{Synthesis of GO-Ag NPs}

GO-Ag nanocomposites were synthesized by a slightly modified method from the reported literature [34]. An amount of $0.5 \mathrm{~g}$ GO powder was sonicated in $30 \mathrm{~mL}$ DI water for $20 \mathrm{~min}$. Then, $8 \mathrm{~g}$ of $\mathrm{NaSH}$ was gradually added and the mixture was maintained at $55^{\circ} \mathrm{C}$ with continuous stirring for $20 \mathrm{~h}$. The product was filtered, washed with DI water and dried in a vacuum oven at $50{ }^{\circ} \mathrm{C}$ for $3 \mathrm{~h}$. The collected GO-SH powder $(0.1 \mathrm{~g})$ was dispersed in $30 \mathrm{~mL}$ of DI water by sonication for $30 \mathrm{~min}$. Subsequently, a series of aqueous solutions including $0.1,0.2$, and $0.25 \mathrm{M}$ of $2 \mathrm{~mL} \mathrm{AgNO}_{3}$ was added to thiolate the GO solution while stirring, respectively. Then, $0.1 \mathrm{M}$ of $20 \mathrm{~mL} \mathrm{NaOH}$ was added to the mixture and stirred for $20 \mathrm{~h}$. The GO-Ag powder was obtained by centrifugation at 10,000 rpm several times and then dried in a vacuum oven at $60^{\circ} \mathrm{C}$ for $24 \mathrm{~h}$. The final dried powder was then filtered using dialysis tubing in order to remove the unreacted salt and loosely bound to Ag NPs. Different concentrations of $\mathrm{AgNO}_{3}$ in the GO nanosheets are referred so-called GO-Ag 0.1 M, GO-Ag 0.2 M, and GO-Ag $0.25 \mathrm{M}$ composites, respectively.

\subsection{Characterizations}

The microscopic images of the pristine GO, Ag, and GO-Ag composites were observed using a transmission electron microscopy (TEM, JEM 2000EXII, JEOL, Tokyo, Japan). In order to compare the distribution of particle size with total counts, the ImageJ software was employed to analyze the full width at half maximum (FWHM) based on the following formulation:

$$
\overline{d n}=\frac{\sum_{i} N \mathrm{i} * d \mathrm{i}}{\sum_{i} N \mathrm{i}}
$$

where $N_{\mathrm{i}}$ is the value of the frequency of counts or number of particles, $d_{\mathrm{i}}$ is the midpoint of classified size [52]. Additionally, the surface microstructure of the samples was determined using a field emission scanning electron microscope (FESEM) (JSM-7500F, Hitachi High-Technologies Corp., Tokyo, Japan) after the specimens were sputtered with gold. The elemental compositions were determined using an energy dispersive X-ray (EDX, Hitachi High-Technologies Corp., Tokyo, Japan) detector equipped with FESEM. The particle size distributions were measured using a dynamic laser light scattering analyzer (Zetasizer, 2000 HAS, Malvern, Worcestershire, UK) at room temperature in triplicates. An X-ray diffraction analyzer (XRD, model D5005D, Siemens AG, Munich, Germany) was used at $2 \theta$ ranging from $5^{\circ}$ to $80^{\circ}$ at a scan rate of $4^{\circ} / \mathrm{min}$ with $\mathrm{Cu} \mathrm{K} \alpha$ radiation. The weight losses of samples were analyzed using a thermogravimetric analyzer (TGA, Model TA-TGA Q-500, TA Instrument, New Castle, DE, USA). Fourier transform infrared spectroscopy (FT-IR) (model Horiba FT-730, Minami-ku, Kyoto, Japan) was used to evaluate the functional groups of GO, GO-SH, and GO-Ag composites. The dried samples were calibrated and recorded in the range of 1000-2000 by a confocal micro-Raman spectroscope (Labram Hr800, Horiba, Ltd., Kyoto, Japan) at a wavelength of $785 \mathrm{~nm}$ under a power of $30 \mathrm{~mW}$. A UV-visible spectrophotometer (V-650, Jasco, Hachioji, Tokyo, Japan) was used to measure light transmittance, and X-ray photoelectron spectroscopy (XPS K-Alpha, VG Microtech MT-500, Thermo Fisher Scientific Inc., Waltham, MA, USA) was used to examine the chemical composition of the samples. Sample suspensions in the cuvette were recorded for zeta potential in triplicates using a dynamic laser scattering analyzer (Zetasizer, $2000 \mathrm{HAS}$, Malvern, Worcestershire, UK) at room temperature after the $\mathrm{pH}$ value was adjusted using $\mathrm{HCl}$ or $\mathrm{NH}_{3}$.

\subsection{Antibacterial Test}

The bacteria strain was kept overnight in a Difco ${ }^{\mathrm{TM}}$ nutrient broth (NB) under aerobic conditions at $37^{\circ} \mathrm{C}$ using a FIRSTEK S300R orbital shaker incubator (FIRSTEK S300R, Nankan, Taoyuan, Taiwan) for $12 \mathrm{~h}$, centrifuged at 10,000 rpm for 5 min using Hermel (Z326K, New Taipei City, Taiwan). The supernatant was discarded and the precipitate was diluted with $12 \mathrm{~mL}$ PBS solution. About $450 \mu \mathrm{L}$ of the above bacterial suspension was transferred into 48 well-plates. Then, $50 \mu \mathrm{L}$ of each 
sample was added (control, GO, Ag NPs, and GO-Ag composites) and kept in an incubator for $1 \mathrm{~h}$. Consequently, $10 \mu \mathrm{L}$ of the sample mixture was taken out and transferred into 96 well-plates and again added $90 \mu \mathrm{L}$ NB. The data was measured by a microplate reader (Biotek, Hong Kong, China) with an IP65LED light (Simon-Tech Inc., Nankan, Taoyuan, Taiwan) as a light source (with an optical density at a wavelength of $600 \mathrm{~nm}$ ) during a $4 \mathrm{~h}$ period. The inhibition efficiency was calculated by using the following equation [53].

$$
\text { Inhibition }(\%)=\left(1-\frac{\Delta \text { OD sample treatment }}{\Delta \text { OD control }}\right) \times 100
$$

The distance between light and the culture plate was $20 \mathrm{~cm}$ and the light energy at that distance was $0.6069537 \mathrm{~J} / \mathrm{cm}^{2}$ for a duration of $15 \mathrm{~min}$. The experiment data were indicated by mean \pm standard deviation $(n=3)$ and a one-way Analysis of Variance (ANOVA) using the GraphPad Prism 7 software to determine whether any significant differences remain between those groups or not. Therein, ${ }^{*} p,^{* *} p$, and ${ }^{* * *} p$ were represented for $p<0.05, p<0.01, p<0.001$, respectively.

\section{Conclusions}

The GO-Ag NPs, via grafting thiol groups, were successfully fabricated without using a stabilizer or a reducing agent. By adding $\mathrm{AgNO}_{3}$ solutions of various concentrations to $\mathrm{GO}$ suspensions, Ag contents of 31\%, 43\%, and 65\% were obtained, with 1-2 nm sizes of Ag NPs anchored on the GO layers. During the synthesis process of GO-Ag, the graphene sheets were fragmented into smaller sizes. These GO-Ag samples have negative surface charges but the GO-Ag $0.2 \mathrm{M}$ sample (43\% Ag) demonstrates the highest antibacterial efficiency. At a 10 ppm load of GO-Ag suspension, only GO-Ag sample containing $43 \%$ of Ag yielded slight bacterial inhibition (5.79-7.82\%). As the GO-Ag content was doubled to $20 \mathrm{ppm}$, the same GO-Ag composite exhibited $\sim 49 \%$ inhibition. When the GO-Ag composite level was raised to $100 \mathrm{ppm}$, almost 100\% of inhibition efficiencies were found on both Staphylococcus aureus (S.A.) and Pseudomonas aeruginosa (P.A.), which were significantly higher than using pristine GO (27\% and 33\% for S.A. and P.A.). The synthesized GO-Ag NPs show potential in both antibacterial and biomedical applications.

Acknowledgments: This work was supported by grants CMRPD2F0052 and CMRPG2G0421 from Chang Gung Memorial Hospital.

Author Contributions: Truong Thi Tuong Vi and Shingiang Jessie Lue planned the research work, did the data analysis, and wrote the full paper; Selvaraj Rajesh Kumar contributed to the paper writing, discussion, and manuscript revision. Bishakh Rout and Chi-Hsien Liu facilitated the bacterial analysis; Chak-Bor Wong, Chia-Wei Chang, Chien-Hao Chen, and Dave W. Chen suggested the research goals and helped in the funding application for this project; All authors examined and approved the final manuscript.

Conflicts of Interest: The authors declare no conflict of interest.

\section{References}

1. Ventola, C.L. The antibiotic resistance crisis: Part 1: Causes and threats. Pharm. Ther. 2015, 40, 277-283.

2. Garazzino, S.; Lutsar, I.; Bertaina, C.; Tovo, P.-A.; Sharland, M. New antibiotics for paediatric use: A review of a decade of regulatory trials submitted to the European Medicines Agency from 2000—Why aren't we doing better? Int. J. Antimicrob. Agents 2013, 42, 99-118. [CrossRef] [PubMed]

3. Graves, J., Jr.; Tajkarimi, M.; Cunningham, Q.; Campbell, A.; Nonga, H.; Harrison, S.; E Barrick, J. Rapid evolution of silver nanoparticle resistance in Escherichia coli. Front. Genet. 2015, 6, 42. [CrossRef] [PubMed]

4. Graves, J.L.; Thomas, M.; Ewunkem, J.A. Antimicrobial nanomaterials: Why evolution matters. Nanomaterials 2017, 7, 283. [CrossRef] [PubMed]

5. Novoselov, K.S.; Geim, A.K.; Morozov, S.V.; Jiang, D.; Zhang, Y.; Dubonos, S.V.; Grigorieva, I.V.; Firsov, A.A. Electric field effect in atomically thin carbon films. Science 2004, 306, 666-669. [CrossRef] [PubMed] 
6. Stankovich, S.; Dikin, D.A.; Dommett, G.H.B.; Kohlhaas, K.M.; Zimney, E.J.; Stach, E.A.; Piner, R.D.; Nguyen, S.T.; Ruoff, R.S. Graphene-based composite materials. Nature 2006, 442, 282-286. [CrossRef] [PubMed]

7. Tegou, E.; Magana, M.; Katsogridaki, A.E.; Ioannidis, A.; Raptis, V.; Jordan, S.; Chatzipanagiotou, S.; Chatzandroulis, S.; Ornelas, C.; Tegos, G.P. Terms of endearment: Bacteria meet graphene nanosurfaces. Biomaterials 2016, 89, 38-55. [CrossRef] [PubMed]

8. Krishnamoorthy, K.; Umasuthan, N.; Mohan, R.; Lee, J.; Kim, S.-J. Antibacterial activity of graphene oxide nanosheets. Sci. Adv. Mater. 2012, 4, 1111-1117. [CrossRef]

9. Zou, X.; Zhang, L.; Wang, Z.; Luo, Y. Mechanisms of the antimicrobial activities of graphene materials. J. Am. Chem. Soc. 2016, 138, 2064-2077. [CrossRef]

10. Nanda, S.S.; Yi, D.K.; Kim, K. Study of antibacterial mechanism of graphene oxide using Raman spectroscopy. Sci. Rep. 2016, 6, 28443. [CrossRef] [PubMed]

11. Prabhu, S.; Poulose, E.K. Silver nanoparticles: Mechanism of antimicrobial action, synthesis, medical applications, and toxicity effects. Int. Nano Lett. 2012, 2, 1-10. [CrossRef]

12. Liu, S.; Zeng, T.H.; Hofmann, M.; Burcombe, E.; Wei, J.; Jiang, R.; Kong, J.; Chen, Y. Antibacterial activity of graphite, graphite oxide, graphene oxide, and reduced graphene oxide: Membrane and oxidative stress. ACS Nano 2011, 5, 6971-6980. [CrossRef] [PubMed]

13. Fernando, K.A.S.; Watson, V.G.; Wang, X.; McNamara, N.D.; JoChum, M.C.; Bair, D.W.; Miller, B.A.; Bunker, C.E. Migration of silver nanoparticles from silver decorated graphene oxide to other carbon nanostructures. Langmuir 2014, 30, 11776-11784. [CrossRef] [PubMed]

14. Li, J.; Kuang, D.; Feng, Y.; Zhang, F.; Xu, Z.; Liu, M.; Wang, D. Green synthesis of silver nanoparticles-graphene oxide nanocomposite and its application in electrochemical sensing oftryptophan. Biosens. Bioelectron. 2013, 42, 198-206. [CrossRef] [PubMed]

15. Hsu, K.-C.; Chen, D.-H. Microwave-assisted green synthesis of Ag/reduced graphene oxide nanocomposite as a surface-enhanced Raman scattering substrate with high uniformity. Nanoscale Res. Lett. 2014, 9, 193. [CrossRef] [PubMed]

16. Li, C.; Wang, X.; Chen, F.; Zhang, C.; Zhi, X.; Wang, K.; Cui, D. The antifungal activity of graphene oxide-silver nanocomposites. Biomaterials 2013, 34, 3882-3890. [CrossRef] [PubMed]

17. Das, M.R.; Sarma, R.K.; Borah, S.C.; Kumari, R.; Saikia, R.; Deshmukh, A.B.; Shelke, M.V.; Sengupta, P.; Szunerits, S.; Boukherroub, R. The synthesis of citrate-modified silver nanoparticles in an aqueous suspension of graphene oxide nanosheets and their antibacterial activity. Colloids Surf. B: Biointerfaces 2013, 105, 128-136. [CrossRef] [PubMed]

18. Haider, M.S.; Badejo, A.C.; Shao, G.N.; Imran, S.M.; Abbas, N.; Chai, Y.G.; Hussain, M.; Kim, H.T. Sequential repetitive chemical reduction technique to study size-property relationships of graphene attached $\mathrm{Ag}$ nanoparticle. Solid State Sci. 2015, 44, 1-9. [CrossRef]

19. Bao, Q.; Zhang, D.; Qi, P. Synthesis and characterization of silver nanoparticle and graphene oxide nanosheet composites as a bactericidal agent for water disinfection. J. Colloid Interface Sci. 2011, 360, 463-470. [CrossRef] [PubMed]

20. Losasso, C.; Belluco, S.; Cibin, V.; Zavagnin, P.; Mičetić, I.; Gallocchio, F.; Zanella, M.; Bregoli, L.; Biancotto, G.; Ricci, A. Antibacterial activity of silver nanoparticles: Sensitivity of different salmonella serovars. Front. Microbiol. 2014, 5, 227. [CrossRef] [PubMed]

21. Zahed, B.; Hosseini-Monfared, H. A comparative study of silver-graphene oxide nanocomposites as a recyclable catalyst for the aerobic oxidation of benzyl alcohol: Support effect. Appl. Surf. Sci. 2015, 328, 536-547. [CrossRef]

22. Trivedi, M.V.; Laurence, J.S.; Siahaan, T.J. The role of thiols and disulfides in protein chemical and physical stability. Curr. Protein Pept. Sci. 2009, 10, 614-625. [CrossRef] [PubMed]

23. Hermanson, G.T. Heterobifunctional Crosslinkers. In Bioconjugate Techniques, 3rd ed.; Academic Press: Boston, MA, USA, 2013; pp. 299-339.

24. He, J.; Zhu, X.; Qi, Z.; Wang, C.; Mao, X.; Zhu, C.; He, Z.; Li, M.; Tang, Z. Killing Dental Pathogens Using Antibacterial Graphene Oxide. ACS Appl. Mater. Interfaces 2015, 7, 5605-5611. [CrossRef] [PubMed]

25. Yang, D.; Velamakanni, A.; Bozoklu, G.; Park, S.; Stoller, M.; Piner, R.D.; Stankovich, S.; Jung, I.; Field, D.A.; Ventrice, C.A.; et al. Chemical analysis of graphene oxide films after heat and chemical treatments by $\mathrm{X}$-ray photoelectron and Micro-Raman spectroscopy. Carbon 2009, 47, 145-152. [CrossRef] 
26. Cushing, S.K.; Li, M.; Huang, F.; Wu, N. Origin of strong excitation wavelength dependent fluorescence of graphene oxide. ACS Nano 2014, 8, 1002-1013. [CrossRef] [PubMed]

27. Li, D.; Muller, M.B.; Gilje, S.; Kaner, R.B.; Wallace, G.G. Processable aqueous dispersions of graphene nanosheets. Nat. Nano 2008, 3, 101-105. [CrossRef] [PubMed]

28. Kumarasinghe, A.R.; Samaranayake, L.; Bondino, F.; Magnano, E.; Kottegoda, N.; Carlino, E.; Ratnayake, U.N.; de Alwis, A.A.P.; Karunaratne, V.; Amaratunga, G.A.J. Self-assembled multilayer graphene oxide membrane and carbon nanotubes synthesized using a rare form of natural graphite. J. Phys. Chem. C 2013, 117, 9507-9519. [CrossRef]

29. Yu, B.; Wang, X.; Xing, W.; Yang, H.; Wang, X.; Song, L.; Hu, Y.; Lo, S. Enhanced thermal and mechanical properties of functionalized graphene/thiol-ene systems by photopolymerization technology. Chem. Eng. J. 2013, 228 (Suppl. C), 318-326. [CrossRef]

30. Glaser, R.E. (Ed.) Vibration spectroscopy tutorial: Sulfur and phosporus. In Organic Spectroscopy; Missouri, MO, USA, 2010. Available online: https:/ / faculty.missouri.edu/ glaserr/8160f10/A03_Silver.pdf (accessed on 1 March 2018).

31. Xu, L.Q.; Yang, W.J.; Neoh, K.-G.; Kang, E.-T.; Fu, G.D. Dopamine-Induced Reduction and Functionalization of Graphene Oxide Nanosheets. Macromolecules 2010, 43, 8336-8339. [CrossRef]

32. Scientific, T. XPS Interpretation of Sodium; Thermo Scientific: Waltham, MA, USA, 2013.

33. Shchukarev, A.V.; Korolkov, D.V. XPS study of group IA carbonates. Cent. Eur. J. Chem. 2004, 2, 347-362. [CrossRef]

34. Kim, J.D.; Yun, H.; Kim, G.C.; Lee, C.W.; Choi, H.C. Antibacterial activity and reusability of CNT-Ag and GO-Ag nanocomposites. Appl. Surf. Sci. 2013, 283, 227-233. [CrossRef]

35. Lukman, A.I.; Gong, B.; Marjo, C.E.; Roessner, U.; Harris, A.T. Facile synthesis, stabilization, and anti-bacterial performance of discrete Ag nanoparticles using Medicago sativa seed exudates. J. Colloid Interface Sci. 2011, 353, 433-444. [CrossRef] [PubMed]

36. Ye, S.; Feng, J. The effect of sonication treatment of graphene oxide on the mechanical properties of the assembled films. RSC Adv. 2016, 6, 39681-39687. [CrossRef]

37. Yang, Y.-K.; He, C.-E.; He, W.-J.; Yu, L.-J.; Peng, R.-G.; Xie, X.-L.; Wang, X.-B.; Mai, Y.-W. Reduction of silver nanoparticles onto graphene oxide nanosheets with $\mathrm{N}, \mathrm{N}$-dimethylformamide and SERS activities of GO/Ag composites. J. Nanopart. Res. 2011, 13, 5571. [CrossRef]

38. Das, M.R.; Sarma, R.K.; Saikia, R.; Kale, V.S.; Shelke, M.V.; Sengupta, P. Synthesis of silver nanoparticles in an aqueous suspension of graphene oxide sheets and its antimicrobial activity. Colloids Surf. B Biointerfaces 2011, 83, 16-22. [CrossRef] [PubMed]

39. Yuan, L.; Jiang, L.; Liu, J.; Xia, Z.; Wang, S.; Sun, G. Facile synthesis of silver nanoparticles supported on three dimensional graphene oxide/carbon black composite and its application for oxygen reduction reaction. Electrochim. Acta 2014, 135, 168-174. [CrossRef]

40. Zheng, L.; Zhang, G.; Zhang, M.; Guo, S.; Liu, Z.H. Preparation and capacitance performance of Ag-graphene based nanocomposite. J. Power Sources 2012, 201, 376-381. [CrossRef]

41. Ahmad, Z.; Afreen, A.; Mehmood, M.; Ali, I.; Asgher, R.; Aziz, M. One-step synthesis of Ag nano-assemblies and study of their antimicrobial activities. J. Nanostruct. Chem. 2015, 5, 325-331. [CrossRef]

42. Dikin, D.A.; Stankovich, S.; Zimney, E.J.; Piner, R.D.; Dommett, G.H.B.; Evmenenko, G.; Nguyen, S.T.; Ruoff, R.S. Preparation and characterization of graphene oxide paper. Nature 2007, 448, 457-460. [CrossRef] [PubMed]

43. Kim, J.D.; Palani, T.; Kumar, M.R.; Lee, S.; Choi, H.C. Preparation of reusable Ag-decorated graphene oxide catalysts for decarboxylative cycloaddition. J. Mater. Chem. 2012, 22, 20665-20670. [CrossRef]

44. Nishimura, S.; Mott, D.; Takagaki, A.; Maenosono, S.; Ebitani, K. Role of base in the formation of silver nanoparticles synthesized using sodium acrylate as a dual reducing and encapsulating agent. Phys. Chem. Chem. Phys. 2011, 13, 9335-9343. [CrossRef] [PubMed]

45. Silhavy, T.J.; Kahne, D.; Walker, S. The Bacterial Cell Envelope. Cold Spring Harbor Perspect. Biol. 2010, 2 , a000414. [CrossRef] [PubMed]

46. Carmel-Harel, O.; Storz, G. Roles of the glutathione- and thioredoxin-dependent reduction systems in the escherichia coli and saccharomyces cerevisiae responses to oxidative stress. Annu. Rev. Microbiol. 2000, 54, 439-461. [CrossRef] [PubMed] 
47. Ravindran, A.; Chandran, P.; Khan, S.S. Biofunctionalized silver nanoparticles: Advances and prospects. Colloids Surf. B Biointerfaces 2013, 105, 342-352. [CrossRef] [PubMed]

48. Tang, J.; Chen, Q.; Xu, L.; Zhang, S.; Feng, L.; Cheng, L.; Xu, H.; Liu, Z.; Peng, R. Graphene oxide-silver nanocomposite as a highly effective antibacterial agent with species-specific mechanisms. ACS Appl. Mater. Interfaces 2013, 5, 3867-3874. [CrossRef] [PubMed]

49. Renner, L.D.; Weibel, D.B. Physicochemical regulation of biofilm formation. MRS Bull. 2011, 36, 347-355. [CrossRef] [PubMed]

50. Dimiev, A.M.; Tour, J.M. Mechanism of graphene oxide formation. ACS Nano 2014, 8, 3060-3068. [CrossRef] [PubMed]

51. Turkevich, J.; Stevenson, P.C.; Hillier, J. A study of the nucleation and growth processes in the synthesis of colloidal gold. Discuss. Faraday Soc. 1951, 11, 55-75. [CrossRef]

52. Markevich, N.; Gertner, I. Comparison among methods for calculating FWHM. Nucl. Instrum. Methods Phys. Res. Sect. A Accel. Spectrom. Detect. Assoc. Equip. 1989, 283, 72-77. [CrossRef]

53. Rout, B.; Liu, C.-H.; Wu, W.-C. Enhancement of photodynamic inactivation against Pseudomonas aeruginosa by a nano-carrier approach. Colloids Surf. B Biointerfaces 2016, 140, 472-480. [CrossRef] [PubMed]

(C) 2018 by the authors. Licensee MDPI, Basel, Switzerland. This article is an open access article distributed under the terms and conditions of the Creative Commons Attribution (CC BY) license (http:/ / creativecommons.org/licenses/by/4.0/). 